\title{
Relações de Trocas e Causalidade de Granger entre Preços Pagos e Recebidos pela Agricultura Brasileira, 1986/2004
}

Nali de Jesus de Souza* Valter José Stülp**

Resumo: O artigo examina as relações de trocas e a causalidade de Granger entre preços pagos e recebidos pela agropecuária brasileira, entre 1986 e 2004. Neste período, houve valorização das relações de trocas para o conjunto da agropecuária. Grande valorização ocorreu até 1994, com forte deterioração em 1995, mantendo-se relativamente estável até 2004. Essa valorização deveu-se ao conjunto dos produtos das lavouras, já que os produtos animais tiveram grande deterioração de suas relações de trocas. Produtos com grande deterioração foram café em coco, trigo, batata inglesa, frango e suínos. Regionalmente, as piores situações para a agropecuária, após 1994, foram as dos estados do Nordeste, exceto Maranhão e Bahia. Quanto à causalidade de Granger, os preços recebidos não causaram os preços pagos totais, nem antes nem após o Plano Real; porém, eles causaram os preços pagos pelos combustíveis, sementes e serviços antes do Plano Real e dos agrotóxicos, sementes e serviços após 1994. O efeito dos preços pagos sobre os recebidos foi maior no primeiro período do que no segundo. Com a abertura da economia, os preços agrícolas passaram a ser influenciados mais por fatores internacionais do que pelos preços internos dos insumos.

\footnotetext{
* Professor de mestrado em Economia do Desenvolvimento da PUCRS. Doutor em Economia. E-mail: nsouza@pucrs.br

** Professor de mestrado em Economia do Desenvolvimento da PUCRS. PhD em Economia. E-mail: stulp@zaz.com.br
} 
Palavras-chave: Relações de trocas, preços agrícolas e causalidade de Granger.

\section{Classificação JEL: C22, O12, Q11}

Abstract - This papers examines the terms of trade and Granger causality between prices received and paid by the Brazilian agricultural sector, from 1986 to 2004. During that period, the terms of trade improved for the agricultural sector. The greatest improvement occurred before 1994; in 1995 the terms of trade fell, followed by a relative stabilization until 2004. The valorization in the whole period was due to agricultural products, since animals products had a significant decline in their terms of trade. Products with the greatest losses were coffee, wheat, potatoes, chicken and hogs. Regionally, the greatest losses, after 1994, occurred in the Northeast States, with the exception of Maranhão and Bahia. The Granger causality shows that agricultural prices did not cause the prices paid, considered as a whole, between 1986/2004; but they caused the prices paid for specific inputs, like fuel oil, seeds and services before 1994, and the prices of pesticides, seeds and services after that year. The effect of the prices paid on the prices received was greater in the first period than in the second one. With the opening of the economy, the prices received became more influenced by external factors than by inputs prices.

Key words: Terms of trade, agricultural prices, Granger causality.

JEL Classification: C22, O12, Q11.

\section{Introdução}

A questão das relações de trocas entre os países subdesenvolvidos, produtores de bens primários, e os países desenvolvidos, industrializados, foi destacada por Prebisch (1949). Ele examinou o índice de preços dos produtos primários em relação ao índice de preços de produtos industrializados e constatou que essa relação caiu de 1 em 1880, para 0,687 em 1945 (Souza, 2005, p. 157). A deterioração das relações de trocas 
contra os países subdesenvolvidos representou transferências de renda dos países pobres para os países ricos, no período.

Essa conclusão produziu um viés contra a agricultura e ênfase na industrialização. Após o trabalho de Johnston \& Mellor (1961), enfatizaram-se as cinco funções da agricultura no desenvolvimento. Porém, se as relações de trocas deteriorarem-se contra a agricultura, ela não poderá transferir poupanças ou consumir bens industriais; com menos recursos para adotar inovações tecnológicas e realizar investimentos, a produção crescerá menos, o que afetará as funções "gerar divisas" e "ofertar alimentos e matérias-primas para os centros urbanos".

A análise de Prebisch sobre as relações de trocas pressupõe independência entre os preços agrícolas $\left(\mathrm{P}_{\mathrm{A}}\right)$ e industriais $\left(\mathrm{P}_{\mathrm{I}}\right)$. Contudo, se eles não forem independentes, a evolução de um deles afetará a magnitude do outro. Desse modo, maior demanda dos produtos agropecuários eleva seus preços, podendo aumentar a demanda dos insumos e de seus preços. O impacto sobre o preço pago será tanto maior quanto mais inelástica for a oferta do fator.

Espera-se que insumos de circulação nacional, como agrotóxicos e fertilizantes, tenham oferta mais elástica, com o preço pouco influenciado pelos preços agrícolas. Já insumos de circulação regional, como sementes e serviços, teriam oferta mais inelástica, tendo preço mais impactado pela demanda, devido a alterações dos preços agrícolas.

O efeito dos preços pagos pelos insumos sobre os preços recebidos pela agropecuária pode ser pensado no contexto da interação da demanda e da oferta nos mercados agrícolas. A mudança do preço pago pelo insumo desloca a curva de oferta do produto agropecuário. Quanto mais inelástica for a curva de demanda pelo produto agropecuário, maior será o impacto sobre o seu preço de equilíbrio. Considera-se a hipótese de que, antes do Plano Real, com a economia mais fechada, as demandas pelos produtos agropecuários seriam mais inelásticas em relação ao período posterior a 1994, pela maior abertura da economia. Por este motivo, supõe-se que os efeitos dos preços pagos sobre os preços recebidos tenham sido mais acentuados antes de 1994 do que após.

Neste contexto, este trabalho examina as relações de trocas da agropecuária brasileira em relação aos principais insumos e analisa a causalidade de Granger entre os preços recebidos pela agropecuária e 
os preços pagos pelos insumos, a partir de junho de 1986. Acredita-se que as relações de trocas beneficiaram a agropecuária antes do Plano Real, com deterioração a partir de 1994, e que a causalidade ocorre no sentido dos preços pagos para os preços recebidos.

\section{Metodologia}

Este estudo utilizou índices mensais de preços recebidos e dos preços pagos pela agropecuária brasileira, relativos a agrotóxicos, fertilizantes, combustíveis, mão-de-obra, sementes e serviços. A análise envolve os períodos de jun. 1986 a jun. 1994 e jul. 1994 a fev. 2004, sendo os dados fornecidos pela FGV-RJ.

As seguintes relações de causalidade de Granger foram testadas, considerando-se a possibilidade de causalidade nos dois sentidos: ${ }^{1}$ a) os preços pagos pela agropecuária (PPA) causam os preços recebidos pela agropecuária (PRA); b) PP agrotóxicos causam os PRA; c) PP fertilizantes causam os PRA; d) PP combustíveis causam os PRA; e) PP sementes causam os PRA; f) PP mão-de-obra causam os PRA; g) PP serviços causam os PRA. Os testes de causalidade utilizam as formas logarítmicas dos índices de preços pagos e dos preços recebidos (logaritmo natural do índice original). Deve-se verificar, inicialmente, se as séries de logaritmos são estacionárias ao nível, ou co-integradas par a par.

\subsection{Teste de estacionariedade das séries}

Para o teste de estacionariedade das séries temporais, utilizou-se a equação 1, com intercepto e termo de tendência, seguindo-se a linha de Patterson (2000, p. 240):

$$
\Delta \mathrm{Y}_{\mathrm{t}}=\alpha+\beta \mathrm{t}+\delta \mathrm{Y}_{\mathrm{t}-1}+\sum_{i=1}^{m} a_{i} \Delta Y_{t-i}+\mathrm{u}_{\mathrm{t}} .
$$

onde $\mathrm{Y}_{\mathrm{t}}$ é o índice de preços na sua forma logarítmica e $t$ é o tempo. $\mathrm{O}$ número de termos defasados considerados $\left(\mathrm{Y}_{\mathrm{t}-\mathrm{i}}\right)$ é aquele que minimiza o valor do Schwarz Information Criterion.

\footnotetext{
${ }^{1}$ Neste texto, ao mencionar o termo causalidade, os autores estão se referindo à causalidade de Granger.
} 
Para testar a significância do coeficiente $\delta$, utilizou-se o teste de Dickey-Fuller Aumentado. Quando a série de dados possui raiz unitária (for não estacionária), verifica-se se as primeiras diferenças são estacionárias ou não. Sendo a série estacionária em primeiras diferenças diz-se que ela é integrada de primeira ordem, ou seja, ela é I(1). No caso de duas séries temporais $\mathrm{Y}_{\mathrm{t}}$ e $\mathrm{X}_{\mathrm{t}}$, integradas de mesma ordem d, testa-se para ver se elas são co-integradas (Patterson, 2000, cap. 8).

\subsection{Teste de causalidade entre as variáveis}

Para este teste, foram utilizadas funções diferentes para variáveis estacionárias ao nível, co-integradas ou não co-integradas.

\subsubsection{Variáveis estacionárias ao nível}

Em relação às séries temporais estacionárias ao nível, realiza-se o teste de causalidade entre os pares, através da estimativa de duas funções (Patterson, 2000, cap. 12). Através da função (2) testa-se se o preço pago $\left(\mathrm{X}_{\mathrm{t}}\right)$ causa o preço recebido $\left(\mathrm{Y}_{\mathrm{t}}\right)$ :

$$
\begin{aligned}
& \mathrm{Y}_{\mathrm{t}}=\alpha_{\mathrm{y}}+\beta_{\mathrm{y} 1} \mathrm{Y}_{\mathrm{t}-1}+\beta_{\mathrm{y} 2} \mathrm{Y}_{\mathrm{t}-2}+\ldots+\beta_{\mathrm{yk}} \mathrm{Y}_{\mathrm{t}-\mathrm{k}}+\gamma_{\mathrm{y} 1} \mathrm{X}_{\mathrm{t}-1}+\gamma_{\mathrm{y} 2} \mathrm{X}_{\mathrm{t}-2}+\ldots+ \\
& \gamma_{\mathrm{yk}} \mathrm{X}_{\mathrm{t}-\mathrm{k}}+\varepsilon_{\mathrm{yt}} .
\end{aligned}
$$

Os $\mathrm{Y}_{\mathrm{t}-\mathrm{i}}$ e os $\mathrm{X}_{\mathrm{t}-\mathrm{i}}$ são as formas logarítmicas dos índices de preços defasados em i períodos (meses). A hipótese nula a ser testada é a seguinte: $\mathrm{H}_{0}: \gamma_{\mathrm{y} 1}=\gamma_{\mathrm{y} 2}=\gamma_{\mathrm{y} 3}=\ldots=\gamma_{\mathrm{yk}}=0$. A hipótese alternativa $\left(\mathrm{H}_{1}\right)$ é a de que pelo menos um dos $\gamma_{\mathrm{yi}}$ seja diferente de zero. Se $\mathrm{H}_{0}$ não for rejeitada, então o preço pago não causa o preço recebido. Para testar se o preço recebido causa o preço pago, usa-se a mesma expressão acima, só que, neste caso, $\mathrm{X}_{\mathrm{t}-\mathrm{i}}$ é o preço recebido e $\mathrm{Y}_{\mathrm{t}-\mathrm{i}}$ é o preço pago.

\subsubsection{Variáveis co-integradas}

Segundo Granger, Huang e Yang (1998), no caso de variáveis $Y_{t}$ e $\mathrm{X}_{\mathrm{t}}$ estacionárias em primeiras diferenças, $\mathrm{I}(1)$, e co-integradas, ou seja, os resíduos $\mathrm{u}_{\mathrm{yt}}$ resultantes da regressão de uma variável sobre a outra 
são I(0), estima-se a função 3 para o teste de causalidade. Esta função destina-se a testar se o preço pago $\left(\mathrm{X}_{\mathrm{t}-\mathrm{i}}\right)$ causa o preço recebido $\left(\mathrm{Y}_{\mathrm{t}}\right)$ :

$$
\begin{aligned}
& \Delta \mathrm{Y}_{\mathrm{t}}=\alpha_{0 \mathrm{y}}+\alpha_{1 \mathrm{y}} \mathrm{u}_{\mathrm{yt}-1}+\beta_{\mathrm{y} 1} \Delta \mathrm{Y}_{\mathrm{t}-1}+\beta_{\mathrm{y} 2} \Delta \mathrm{Y}_{\mathrm{t}-2}+\ldots+\beta_{\mathrm{yk}} \Delta \mathrm{Y}_{\mathrm{t}-\mathrm{k}}+\gamma_{\mathrm{y} 1} \Delta \mathrm{X}_{\mathrm{t}-1}+\gamma_{\mathrm{y} 2} \Delta \mathrm{X}_{\mathrm{t}-2} \\
& +\ldots+\gamma_{\mathrm{yk}} \Delta \mathrm{X}_{\mathrm{t}-\mathrm{k}}+\varepsilon_{\mathrm{yt}}
\end{aligned}
$$

Aqui $\Delta$ é o operador de primeira diferença e $u_{\mathrm{yt}-1}$ são os resíduos defasados em um período da função $\mathrm{Y}_{\mathrm{t}}=\alpha_{\mathrm{y}}+\beta_{\mathrm{y}} \mathrm{X}_{\mathrm{t}}+\mathrm{u}_{\mathrm{yt}}$. A hipótese nula é: $\mathrm{H}_{0}: \alpha_{1 \mathrm{y}}=\gamma_{\mathrm{y} 1}=\gamma_{\mathrm{y} 2}=\gamma_{\mathrm{y} 3}=\ldots=\gamma_{\mathrm{yk}}=0$. A hipótese alternativa $\left(\mathrm{H}_{1}\right)$ é a que pelo menos um dos $\gamma_{\mathrm{yi}}$ e/ou $\alpha_{1 \mathrm{y}}$ seja diferente de zero. Se $\mathrm{H}_{0}$ não for rejeitado, o preço pago não causa o preço recebido. Para testar se o preço recebido causa o preço pago, utiliza-se a mesma expressão acima, só que, neste caso, $\mathrm{X}_{\mathrm{t}}$ é o preço recebido e $\mathrm{Y}_{\mathrm{t}-\mathrm{i}}$ é o preço pago.

\subsubsection{Variáveis não co-integradas}

Segundo Granger, Huang e Yang (1998), no caso das variáveis $\mathrm{Y}_{\mathrm{t}}$ e $\mathrm{X}_{\mathrm{t}}$ serem estacionárias em primeiras diferenças, I(1), e os resíduos $\mathrm{u}_{\mathrm{yt}}$ não serem I(0) (as variáveis não serem co-integradas), o teste de causalidade seria feito através da equação (4). Esta equação destina-se a testar se o preço pago $\left(\mathrm{X}_{\mathrm{t}-\mathrm{i}}\right)$ causa o preço recebido $\left(\mathrm{Y}_{\mathrm{t}}\right)$ :

$$
\begin{aligned}
& \Delta \mathrm{Y}_{\mathrm{t}}=\alpha_{0 \mathrm{y}}+\beta_{\mathrm{y} 1} \Delta \mathrm{Y}_{\mathrm{t}-1}+\beta_{\mathrm{y} 2} \Delta \mathrm{Y}_{\mathrm{t}-2}+\ldots+\beta_{\mathrm{yk}} \Delta \mathrm{Y}_{\mathrm{t}-\mathrm{k}}+\gamma_{\mathrm{y} 1} \Delta \mathrm{X}_{\mathrm{t}-1}+\gamma_{\mathrm{y} 2} \Delta \mathrm{X}_{\mathrm{t}-2}+ \\
& \ldots+\gamma_{\mathrm{yk}} \Delta \mathrm{X}_{\mathrm{t}-\mathrm{k}}+\varepsilon_{\mathrm{yt}} .
\end{aligned}
$$

A hipótese nula $\left(\mathrm{H}_{0}\right)$ é: $\gamma_{\mathrm{y} 1}=\gamma_{\mathrm{y} 2}=\gamma_{\mathrm{y} 3}=\ldots=\gamma_{\mathrm{yk}}=0$. A hipótese alternativa $\left(\mathrm{H}_{1}\right)$ é a de que pelo menos um dos $\gamma_{\mathrm{yi}}$ seja diferente de zero. Se $\mathrm{H}_{0}$ não for rejeitada, o preço pago não causa o preço recebido. Para testar se o preço recebido causa o preço pago, usa-se a expressão (4) acima, só que, neste caso, $\mathrm{X}_{\mathrm{t}-\mathrm{i}}$ é o preço recebido e $\mathrm{Y}_{\mathrm{t}}$ é o preço pago.

\section{Relações de trocas da agricultura brasileira}

No início da década de 1980, as políticas de estabilização do Brasil reduziram o crédito rural, com aumento das taxas de juros cobradas nos empréstimos. Para compensar os agricultores, o governo fortaleceu 
a política de garantia de preços mínimos. Os instrumentos foram as Aquisições do Governo Federal e os Empréstimos do Governo Federal. O setor agrícola também se beneficiou da menor proteção à indústria, da eliminação de impostos e do fim das restrições quantitativas às exportações agropecuárias (Helfand \& Rezende, 2001, p. 252).

Nos anos 90, a liberalização comercial alterou preços relativos e facilitou o acesso a insumos importados mais baratos e de melhor qualidade. Com a redução de custos, cresceu a competitividade interna. Entre 1990/91 não houve aquisições do governo, pela falta de recursos e porque os preços de mercado estavam bem acima dos preços mínimos. A política de sustentação de preços foi retomada entre 1992/95 (Helfand \& Rezende, 2001, p. 257).

Em 1995, como os estoques estavam muito altos, o governo mudou a política de garantia de preços ao criar o Prêmio de Escoamento da Produção. Um bônus era concedido aos compradores de produtos agropecuários pelos preços mínimos. Porém, essa nova política não foi eficiente para garantir preços mínimos para a agricultura. No caso do milho, o preço mínimo caiu $27 \%$ em termos reais, desde 1995. Os agricultores não reclamaram porque a dívida agrícola foi renegociada com base nos preços mínimos (Helfand \& Rezende, 2001, p. 259).

A política de preços mínimos visava produtos básicos de consumo interno, cuja oferta desejava-se estimular, como milho, arroz, feijão, soja, algodão e mandioca. Na década de 1990, os mercados foram desregulamentados para cana-de-açúcar, leite, café e trigo, este incluído na política de preços mínimos. Os mercados ficaram mais competitivos, resultando no aumento da produtividade, queda de custos e dos preços agrícolas (Rezende, 2003, p. 234). ${ }^{2}$

As reformas da política agrícola das décadas de 1980 e 1990 afetaram negativamente os preços dos produtos importáveis, principalmente leite e trigo; enquanto os produtos exportáveis foram beneficiados, notadamente cacau, laranja e soja. Percebe-se que a taxa de câmbio real influencia decisivamente os preços internos dos produtos agropecuários, o que ajuda a explicar as variações dos termos de trocas (Helfand \& Rezende, 2001, p. 267 e 271).

\footnotetext{
2 Segundo Alves (2001), a redução dos preços agrícolas ao nível de varejo representa, quase sempre, uma queda mais acentuada dos preços ao nível do produtor agrícola.
} 
As relações de trocas (preços recebidos/preços pagos) foram favoráveis para o conjunto da agropecuária, passando de 100 em jun. 1986 para 120,9 em fev. 2004 (Tabela 1, col. 1); em dez. 1994, elas alcançaram um pico de 159. ${ }^{3}$ Após dez. 1988, as relações de trocas pioraram para a agropecuária, melhorando a partir de 1992. Após o Plano Real, seguiu-se um período de relativa estabilidade dessas relações, com declínio no início da desvalorização cambial de 1999, quando os insumos importados ficaram mais caros.

Tabela 1 - Relações de trocas da agropecuária brasileira, jun.1986 a fev. 2004

\begin{tabular}{|c|c|c|c|c|c|c|c|}
\hline Meses & $\begin{array}{l}\text { IPRA/ } \\
\text { IPPA }\end{array}$ & \begin{tabular}{c|} 
IPRA/ \\
IPP \\
Sementes
\end{tabular} & \begin{tabular}{|c|} 
IPRA/ \\
IPP Fertiliz.
\end{tabular} & $\begin{array}{c}\text { IPRA/ } \\
\text { IPP } \\
\text { Agrotóxicos }\end{array}$ & $\begin{array}{c}\text { IPRA/ } \\
\text { IPP } \\
\text { Serviços }\end{array}$ & \begin{tabular}{|c|} 
IPRA/ \\
IPP \\
Combust
\end{tabular} & $\begin{array}{c}\text { IPRA/ } \\
\text { IPP } \\
\text { M.obra }\end{array}$ \\
\hline dez.86 & 104,1 & 98,6 & 117,4 & 115,9 & 119,0 & 126,5 & 79,3 \\
\hline dez.87 & 86,9 & 106,0 & 81,8 & 86,7 & 63,1 & 82,2 & 98,3 \\
\hline dez.88 & 111,3 & 97,9 & 101,5 & 107,8 & 94,6 & 113,8 & 158,5 \\
\hline dez.89 & 84,0 & 104,6 & 76,3 & 74,7 & 48,7 & 110,7 & 99,2 \\
\hline dez.90 & 96,2 & 105,8 & 90,6 & 97,4 & 61,2 & 116,4 & 107,0 \\
\hline dez.91 & 94,4 & 109,0 & 96,5 & 84,3 & 51,2 & 98,7 & 115,1 \\
\hline dez.92 & 113,3 & 119,8 & 125,5 & 107,8 & 54,7 & 106,1 & 149,9 \\
\hline dez.93 & 130,1 & 137,3 & 156,3 & 124,3 & 68,7 & 102,0 & 164,1 \\
\hline dez.94 & 159,5 & 150,8 & 185,6 & 138,4 & 85,7 & 135,3 & 124,6 \\
\hline dez.95 & 115,2 & 141,7 & 150,8 & 137,2 & 72,0 & 122,5 & 83,2 \\
\hline dez.96 & 115,4 & 135,2 & 150,0 & 142,6 & 77,5 & 131,2 & 80,4 \\
\hline dez.97 & 122,2 & 143,7 & 167,9 & 148,1 & 81,7 & 130,0 & 84,4 \\
\hline dez.98 & 124,1 & 139,8 & 174,0 & 147,6 & 84,2 & 135,9 & 85,0 \\
\hline dez.99 & 121,2 & 149,3 & 150,4 & 126,9 & 88,7 & 111,1 & 96,2 \\
\hline dez.00 & 114,1 & 143,0 & 147,2 & 121,4 & 85,2 & 90,0 & 93,4 \\
\hline Dez.01 & 117,5 & 145,8 & 150,5 & 126,3 & 86,5 & 90,5 & 99,2 \\
\hline Dez.02 & 132,1 & 146,4 & 171,6 & 147,9 & 101,9 & 87,7 & 127,2 \\
\hline Dez-03 & 124,0 & 133,8 & 158,4 & 142,0 & 85,4 & 88,5 & 121,5 \\
\hline Fev-04 & 120,9 & 130,6 & 150,0 & 138,3 & 83,4 & 88,0 & 120,4 \\
\hline
\end{tabular}

Fonte dos dados brutos: FGV/RJ (junho de $1986=100$ ).

${ }^{3}$ Considerando o período de 1975/2000, Barros e Rizzieri (Apud Alves, 2001) mostraram que houve queda dos preços agrícolas ao consumidor. Isto revelaria uma enorme transferência de renda do setor agrícola para o consumidor final. Esta queda teria ocorrido durante todo o conjunto do período e não apenas em anos específicos. 
Embora as relações de trocas da agropecuária tenham sido favoráveis, considerando-se o conjunto dos insumos $(+20,9 \%)$, o mesmo não se pode dizer em relação a insumos específicos, como serviços e combustíveis, cuja relação chegou em fevereiro de 2004, respectivamente, a 83,4 e a 88,0. Períodos favoráveis para a agropecuária em relação a combustíveis ocorreram em 1986, 1988 a 1990 e 1992 a 1999. Após 1999, com o repasse do choque cambial para os preços dos combustíveis, as relações de trocas caíram contra a agropecuária em relação a esse insumo.

Figura 1 - Relações de troca da agricultura brasileira, jun.1986/fev.2004 (Total agropecuária)

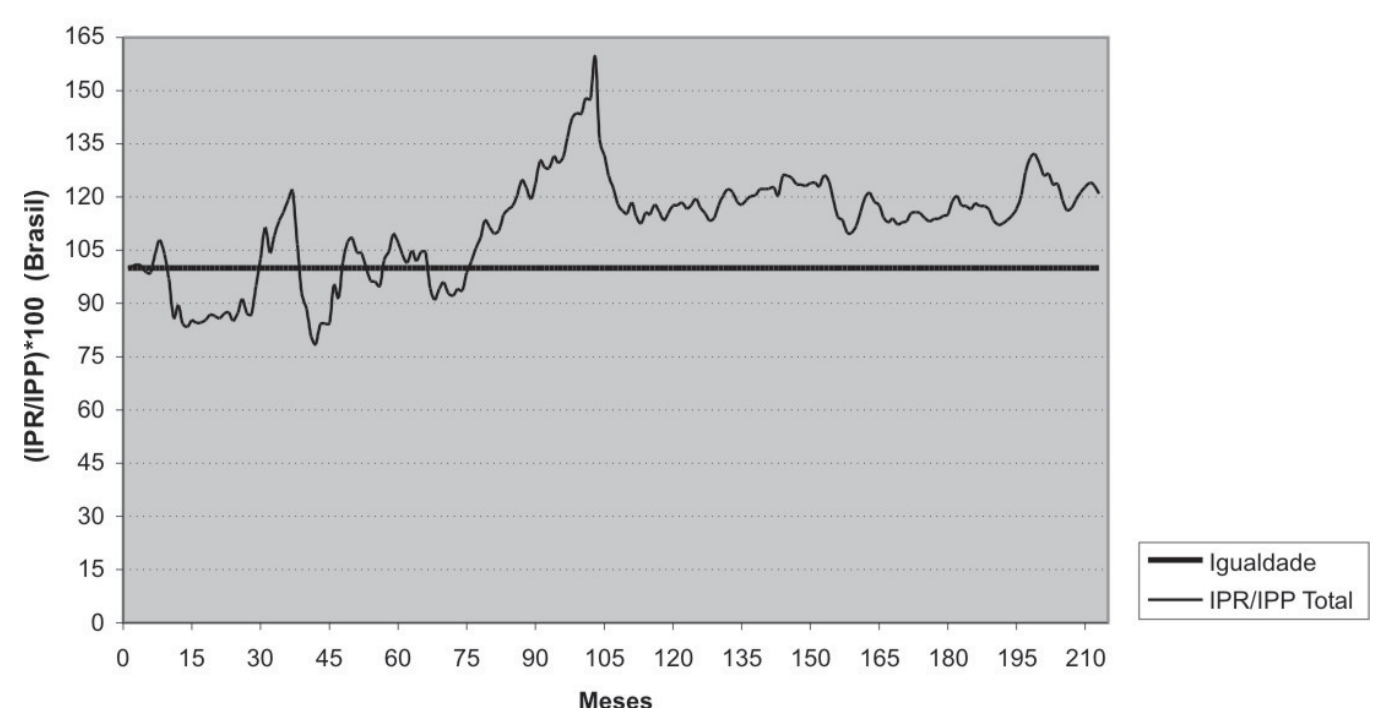

Para os serviços, a deterioração contra a agropecuária ocorreu entre 1987/2001, com uma grande melhoria em 2002, para deteriorar-se em 2003 e 2004. Em relação a esse insumo, os piores anos para as relações de trocas da agropecuária foram os anos de inflação alta, com uma ligeira melhoria após a implantação do Plano Real. ${ }^{4}$

As maiores vantagens para a agropecuária ocorreram no caso dos fertilizantes (150,0 em fev. 2004), agrotóxicos $(138,3)$ e sementes $(130,6)$.

\footnotetext{
${ }^{4}$ Segundo Rezende (2003, cap.4), entre 1986/91, houve relação inversa entre preços relativos agrícolas (preços recebidos/preços pagos) e taxa de inflação. Em períodos de inflação alta, os detentores de riqueza não estariam interessados em reter estoques de produtos agrícolas, mas sim ativos financeiros indexados à inflação. Com esta decisão, eles aumentam as vendas de seus produtos, forçando a baixa de preços. Nos períodos de inflação baixa, os produtos agrícolas seriam utilizados como reserva de valor, aumentando, portanto, seus preços.
} 
Em relação aos fertilizantes, os períodos desfavoráveis foram 1987 e 1989 a 1991, com grandes vantagens para a agropecuária a partir de 1992, com picos em 1994, 1998 e 2002. Trajetória similar ocorreu em relação aos agrotóxicos.

No caso das sementes, os períodos de deterioração foram 1986 e 1988 e os de maior valorização ocorreram em 1987, 1999 e 2002. Em relação à mão-de-obra, a agropecuária manteve os $20 \%$ de valorização do conjunto dos preços pagos, com picos em 1988, 1992 e 1993. Em geral, os salários desindexados se valorizaram em relação aos preços recebidos. Melhoria das relações de trocas em relação a esse insumo ocorreu a partir de 2002.

A valorização cambial até 1999 afetou as exportações e aumentou a oferta interna de produtos importados, reduzindo os preços. A melhoria das relações de trocas em benefício da agropecuária, após dez. 2000, pode ser vista, também, na última linha da Tabela 2, que mostra a evolução das relações de trocas da agropecuária dos principais estados produtores, entre dez. 1998 e fev. 2004.

As relações de trocas deterioraram-se a partir de dez. 1998 contra alguns estados $(1994=100)$, sendo os mais afetados PB (fev. $2004=$ $77,0)$, RN $(79,1)$, MG $(87,1)$ e CE $(87,4)$. As relações de trocas pioraram também para PE $(91,4)$, PR $(91,7)$, SP $(93,3)$, MS $(95,1)$, GO $(95,4)$ e SC $(96,5)$. As relações de trocas foram favoráveis para MA $(142,4)$, BA $(122,2)$, RS $(107,9)$ e MT $(104,6)$.

A Tabela 3 apresenta a evolução das relações de trocas para o conjunto da agropecuária, para todo o período (jun. 1986 = 100). No final do período (fev. 2004), percebe-se que pioraram as relações de trocas para a maioria dos produtos, sobretudo para os produtos de origem animal (frango, suíno, leite), mas afetando também algumas culturas, como café, batata, trigo, feijão e milho. Apesar disso, as relações de trocas foram favoráveis para o conjunto das Lavouras $(136,6)$, com destaque para Fumo $(102,8)$ e Soja $(100,2)$; para grande parte desses produtos, elas melhoraram até fins de 1994, piorando após. 
Tabela 2 - Relações de trocas da agropecuária brasileira em alguns estados (dez. 98 a fev. 2004)

\begin{tabular}{l|c|c|c|c|c|c|c}
\hline \multicolumn{1}{c|}{ Estados } & Dez.98 & dez.99 & dez.00 & dez.01 & dez.02 & dez.03 & fev.04 \\
\hline Maranhão & 106,6 & 114,7 & 100,4 & - & 125,9 & 143,9 & 142,4 \\
Ceará & 82,8 & 76,0 & 75,0 & 68,8 & 86,5 & 88,6 & 87,4 \\
Rio Grande do Norte & 82,6 & 75,6 & 67,8 & 63,0 & 67,1 & 79,7 & 79,1 \\
Paraíba & 71,9 & 69,0 & 65,7 & 66,8 & 70,1 & 76,6 & 77,0 \\
Pernambuco & 74,2 & 69,1 & 69,0 & 79,3 & 92,8 & 88,1 & 91,4 \\
Bahia & 96,4 & 88,1 & 75,1 & 99,8 & 142,9 & 117,2 & 122,2 \\
Minas Gerais & 73,2 & 91,6 & 82,2 & 84,0 & 96,1 & 89,6 & 87,1 \\
São Paulo & 92,9 & 89,4 & 94,2 & 92,3 & 103,6 & 95,6 & 93,3 \\
Paraná & 96,5 & 95,7 & 87,5 & 91,6 & 110,6 & 93,6 & 91,7 \\
Santa Catarina & 96,3 & 99,5 & 93,2 & 104,4 & 110,0 & 102,5 & 96,5 \\
Rio Grande do Sul & 99,3 & 94,3 & 92,2 & 105,9 & 118,1 & 112,3 & 107,9 \\
Mato Grosso do Sul & 91,7 & 93,9 & 85,8 & 84,8 & 92,3 & 101,4 & 95,1 \\
Mato Grosso & 102,5 & 89,0 & 82,7 & 95,2 & 99,9 & 106,6 & 104,6 \\
Goiás & 93,8 & 96,9 & 85,8 & 89,5 & 108,8 & 101,6 & 95,4 \\
\hline Brasil & 86,4 & 84,4 & 79,4 & 81,8 & 92,0 & 86,3 & 84,2 \\
\hline
\end{tabular}

Fonte dos dados brutos: FGV/RJ (agosto de $1994=100$ ).

A valorização cambial do início do Plano Real, ao reduzir a competitividade externa, elevou a oferta agrícola interna, afetando os preços. Agiu no mesmo sentido a expansão da fronteira agrícola, facilitada pela redução de preços nas importações de insumos, máquinas e equipamentos para a agropecuária.

Os estados especializados na produção de soja (RS, MT, MA) e cacau (BA) tiveram relações de trocas favoráveis, como foi visto na Tabela 2. A partir de 1999, a desvalorização cambial tornou o setor agrícola mais competitivo no mercado internacional resultando na grande expansão da produção entre 2000 e 2002, melhorando as relações de trocas principalmente para as commodities. O aumento da renda permitiu a adoção mais intensa de inovações tecnológicas nessas culturas, principalmente naquelas vinculadas ao complexo agroindustrial. 
Tabela 3 - Índice das relações de trocas do total da agropecuária e alguns produtos, dez.86/fev. 04 (Jun.86 = 100).

\begin{tabular}{l|c|c|c|c|c|c|c|c|c|c|c}
\hline \multicolumn{1}{c|}{ Produtos } & dez-86 & dez-88 & dez-90 & dez-92 & dez/93 & dez-94 & dez-96 & dez-98 & dez-00 & dez-02 & fev-04 \\
\hline Lavouras & 94,6 & 105,4 & 93,6 & 111,7 & 128,9 & 154,5 & 122,2 & 139,2 & 118,4 & 154,1 & 136,6 \\
Algodão & 98,0 & 76,5 & 60,5 & 77,4 & 77,9 & 97,1 & 80,4 & 68,8 & 71,9 & 69,4 & 91,2 \\
Arroz em casca & 89,4 & 92,2 & 96,2 & 86,1 & 93,5 & 96,1 & 70,3 & 93,6 & 53,4 & 78,4 & 91,5 \\
Batata inglesa & 105,7 & 43,7 & 75,2 & 45,3 & 42,9 & 92,6 & 34,9 & 55,9 & 57,7 & 44,6 & 31,2 \\
Cacau & 91,1 & 100,7 & 47,4 & 47,6 & 65,3 & 52,3 & 54,6 & 60,9 & 44,1 & 156,9 & 77,6 \\
Café em coco & 76,6 & 31,1 & 18,3 & 25,6 & 27,2 & 52,5 & 28,4 & 35,6 & 24,3 & 21,6 & 20,1 \\
Cana-de-açúcar & 106,4 & 108,4 & 101,4 & 93,8 & 115,8 & 124,5 & 112,8 & 105,6 & 121,2 & 96,2 & 87,1 \\
Feijão & 102,6 & 112,2 & 80,9 & 95,4 & 124,9 & 112,4 & 76,3 & 127,9 & 56,4 & 88,1 & 61,1 \\
Fumo em folha & 82,3 & 107,5 & 84,4 & 129,3 & 138,5 & 129,7 & 117,3 & 109,3 & 93,9 & 85,5 & 102,8 \\
Laranja & 96,6 & 148,1 & 71,2 & 74,1 & 99,4 & 153,5 & 64,4 & 99,7 & 54,8 & 116,0 & 86,6 \\
Milho & 97,0 & 120,1 & 103,5 & 99,7 & 108,9 & 98,6 & 70,9 & 70,5 & 59,3 & 102,5 & 62,8 \\
Soja & 86,2 & 151,9 & 77,5 & 96,9 & 102,9 & 85,1 & 87,0 & 68,3 & 75,4 & 122,2 & 100,2 \\
Trigo em grão & 81,3 & 60,0 & 35,5 & 43,8 & 37,9 & 44,2 & 29,6 & 29,4 & 33,8 & 53,1 & 36,1 \\
Prod. animais & 124,1 & 119,5 & 92,6 & 106,3 & - & 152,7 & 92,8 & 89,9 & 94,6 & 87,4 & 84,4 \\
Boi gordo & 156,3 & 118,7 & 76,7 & 93,8 & 120,3 & 129,3 & 70,0 & 77,7 & 87,1 & 79,0 & 70,6 \\
Frango p/corte & 115,3 & 110,1 & 79,6 & 82,2 & 107,8 & 102,9 & 60,4 & 55,4 & 56,1 & 56,9 & 50,8 \\
Leite & 105,1 & 115,7 & 100,0 & 91,2 & 87,0 & 139,4 & 93,1 & 79,7 & 78,2 & 74,2 & 69,0 \\
Suíno p/corte & 122,2 & 104,7 & 65,2 & 87,7 & 106,2 & 115,2 & 64,4 & 62,3 & 66,6 & 51,6 & 54,7 \\
Brasil & 104,1 & 111,3 & 96,2 & 113,3 & 94,2 & 159,5 & 115,4 & 124,1 & 114,1 & 132,1 & 120,9 \\
\hline
\end{tabular}

Fonte dos dados brutos: FGV/RJ.

Obs.: Para cada produto, os índices foram calculados em relação aos preços pagos pelo conjunto da agropecuária.

\section{Análise de causalidade entre os índices de preços}

\subsection{Teste de raiz unitária dos índices de preços.}

Tanto em relação ao período de 06/1986 a 06/1994, como ao de 07/1994 a 02/2004, não se pode rejeitar a hipótese de raiz unitária em relação a nenhuma das séries de índices de preços, na sua forma logarítmica, considerada ao nível, com exceção da mão-de-obra no segundo período. Portanto, todas as séries de preços, com exceção da deste último fator, são não estacionárias (Tabela 4). 
Quando as séries de preços são consideradas em primeiras diferenças, rejeita-se a hipótese de raiz unitária em relação a todas elas, com exceção do preço da mão-de-obra para o período de 06/1986 a 06/1994. Portanto, em primeiras diferenças todas as séries são estacionárias com exceção da mão-de-obra, no primeiro período, a qual é estacionária em segundas diferenças (Tabela 5).

Tabela 4 - Valores do teste de Dickey-Fuller Aumentado (ADF) de raiz unitária ao nível, com intercepto e termo de tendência, para séries de índices de preços, nas formas logarítmicas.

\begin{tabular}{l|c|c|c|c}
\hline \multirow{2}{*}{ Índice de preços } & \multicolumn{2}{|c|}{ Período 06/1986 a 06/1994 } & \multicolumn{2}{c}{ Período 07/1994 a 02/2004 } \\
\cline { 2 - 5 } & ADF & $\begin{array}{c}\text { Significância } \\
\text { estatística }\end{array}$ & ADF & $\begin{array}{c}\text { Significância } \\
\text { estatística }^{(1)}\end{array}$ \\
\hline 1 - Recebidos pela agropecuária & $-1,7941$ & 0,700 & $-2,3578$ & 0,400 \\
2 - Pagos por: & $-2,2118$ & 0,477 & $-1,2113$ & 0,903 \\
- Índice global & $-2,0023$ & 0,592 & $-2,1445$ & 0,515 \\
- Agrotóxicos. & $-2,0673$ & 0,557 & $-1,9232$ & 0,636 \\
- Combustíveis & $-2,2574$ & 0,453 & $-0,8784$ & 0,954 \\
- Fertilizantes & $-1,9572$ & 0,616 & $-9,4694$ & 0,000 \\
- Mão de obra & $-2,1320$ & 0,521 & $-0,5662$ & 0,979 \\
- Sementes & $-2,4921$ & 0,331 & 1,4163 & 1,000 \\
- Serviços & & &
\end{tabular}

Nota: (1) valores de MacKinnon para o teste unilateral.

Portanto, todas as séries de preços, na sua forma logarítmica, nos dois períodos, são integradas de primeira ordem, ou seja, I(1). Faz exceção apenas a série de preços da mão-de-obra que é I(2) no primeiro período e I(0) no segundo período. Como os preços pagos pela mão-deobra não são da mesma ordem de integração que os preços recebidos pelos produtos agropecuários, não se analisa a causalidade entre estes e os preços daquele fator. Para analisar a causalidade entre os preços recebidos e os pagos pelos demais fatores procede-se aos testes de cointegração entre os mesmos. 
Tabela 5 - Valores do teste de Dickey-Fuller Aumentado (ADF)

de raiz unitária para as séries dos índices de preços, nas suas formas logarítmicas.

Séries em primeiras diferenças.

\begin{tabular}{|c|c|c|c|c|}
\hline \multirow[t]{2}{*}{ Índice de preços } & \multicolumn{2}{|c|}{ Período 06/1986 a 06/1994 } & \multicolumn{2}{|c|}{ Período 07/1994 a 02/2004 } \\
\hline & ADF & \begin{tabular}{|c|}
$\begin{array}{c}\text { Significância } \\
\text { estatística }^{(1)}\end{array}$
\end{tabular} & $\mathrm{ADF}$ & $\begin{array}{c}\text { Significância } \\
\text { estatística }^{(1)}\end{array}$ \\
\hline $\begin{array}{l}1 \text { - Recebidos pela agropecuária } \\
2 \text { - Pagos por: }\end{array}$ & $-3,8348$ & 0,019 & $-5,6758$ & 0,000 \\
\hline - Índice global & $-3,9971$ & 0,012 & $-12,6766$ & 0,000 \\
\hline - Agrotóxicos. & $-4,1426$ & 0,008 & $-13,0327$ & 0,000 \\
\hline - Combustíveis & $-5,1038$ & 0,000 & $-9,5378$ & 0,000 \\
\hline - Fertilizantes & $-3,8759$ & 0,017 & $-5,6496$ & 0,000 \\
\hline - Mão de obra & $-3,1134$ & 0,110 & $-8,2960$ & 0,000 \\
\hline - Sementes & $-3,7087$ & 0,027 & $-12,5474$ & 0,000 \\
\hline - Serviços & $-4,7708$ & 0,001 & $-8,8694$ & 0,000 \\
\hline
\end{tabular}

Nota: (1) valores de MacKinnon para o teste unilateral.

\subsection{Testes de co-integração}

Para o teste de co-integração regressa-se à forma logarítmica do índice de preços recebidos sobre as formas logarítmicas de cada um dos índices de preços pagos. Procede-se, a seguir, aos testes de raízes unitárias de cada uma das séries de resíduos destas regressões.

Segundo PATTERSON (2000), os valores críticos utilizados no teste de raiz unitária dos resíduos diferem dos utilizados para o teste das outras variáveis porque os resíduos são valores estimados e não observados. PATERSON (2000, p. 372) apresenta a seguinte expressão para o cálculo dos valores críticos a serem utilizados no teste de raiz unitária dos resíduos: $\mathrm{C}(\alpha, \mathrm{T})=\mathrm{K}_{\infty}+\mathrm{K}_{1} / \mathrm{T}+\mathrm{K}_{2} / \mathrm{T}^{2}$. Os valores dos $\mathrm{K}$ variam conforme o nível de significância estatística $\alpha$. Para o teste com constante e termo de tendência os valores dos $\mathrm{K}$ são: a) para $\alpha .=1 \%: \mathrm{K}_{\infty}=-4,3268 ; \mathrm{K}_{1}=-15,531$ e $\mathrm{K}_{2}$ $=-34,03$; b) para $\alpha .=5 \%: \mathrm{K}_{\infty}=-3,7809 ; \mathrm{K}_{1}=-9,421$ e $\mathrm{K}_{2}=-15,06$; ) para $\alpha .=10 \%: \mathrm{K}_{\infty}=-3,4959 ; \mathrm{K}_{1}=-7,203$ e $\mathrm{K}_{2}=-4,01$. Os valores de $\mathrm{T}$ são o número de observações em cada período considerado.

Os valores críticos obtidos para as séries referentes ao período de 06/1986 a 06/1994 são -4,4921, -3,8807 e -3,5714, respectivamente, para os níveis de significância estatística de 1\%, 5\% e 10\%. Em relação ao período 07/1994 a 02/2004 os valores críticos são -4,4642, $-3,8640$ e -3,5588, respectivamente, para significância estatística de $1 \%, 5 \%$ e $10 \%$. 
Tabela 6 - Valores da estatística t do teste de Dickey-Fuller Aumentado (ADF) de raiz unitária dos resíduos das regressões do logaritmo do índice de preços recebidos sobre os logaritmos dos índices de preços pagos.

\begin{tabular}{l|c|c}
\hline \multirow{2}{*}{ Preços pagos } & \multicolumn{2}{|c}{ Estatística t do teste ADF } \\
\cline { 2 - 3 } & $\begin{array}{c}\text { Período de 06/1986 } \\
\text { a 06/1994 }\end{array}$ & $\begin{array}{c}\text { Período de 07/1994 } \\
\text { a 02/2004 }\end{array}$ \\
\hline Índice global & -2.9226 & -3.2875 \\
- Agrotóxicos & $-3,2363$ & $-1,8307$ \\
- Combustíveis & $-2,5230$ & $-2,9948$ \\
- Fertilizantes & $-3,0919$ & $-2,0987$ \\
- Sementes & $-5,1942$ & $-3,7017$ \\
- Serviços & $-2,4864$ & $-2,9864$ \\
\hline
\end{tabular}

Fonte: Cálculo dos autores.

Os valores da estatística t do teste de Dickey-Fuller Aumentado de raiz unitária dos resíduos das regressões constam na Tabela 6. Em relação aos dois períodos, todos os valores absolutos da estatística t são menores que os valores críticos correspondentes ao nível de significância de $10 \%$. Portanto, as séries de resíduos são não estacionárias. Excetuam-se apenas as duas séries de resíduos referentes às sementes. Assim, a série dos preços recebidos é co-integrada com a série dos preços pagos pelas sementes nos dois períodos, mas não com cada uma das outras séries dos preços pagos.

\subsection{Análise da causalidade de Granger entre preços recebidos e preços pagos.}

Os resultados dos testes de causalidade de Granger entre preços recebidos e pagos encontram-se na Tabela 7 . Considerando significância estatística de $10 \%$, os preços recebidos não causaram os preços pagos pelos insumos no período de 06/1986 a 06/1994, quando considerados no seu conjunto. Em relação aos insumos específicos, verifica-se que os preços recebidos também não causaram os preços pagos pelos agrotóxicos e fertilizantes. Eles causaram os preços pagos pelos combustíveis, sementes e serviços. Em relação ao período de 07/1994 a 02/2004, os preços recebidos também não causaram os preços pagos pelo conjunto dos insumos. Os preços recebidos não causaram os preços pagos pelos combustíveis e fertilizantes, mas causaram os preços pagos pelos agrotóxicos, sementes e serviços. 
Tabela 7 - Testes de causalidade de Granger entre preços recebidos e preços pagos pela agropecuária brasileira nos períodos de 06/1986 a 06/1994 e 07/1994 a 02/2004.

Teste de Wald.

\begin{tabular}{|c|c|c|c|c|c|c|c|c|}
\hline \multirow{3}{*}{ Preços pagos } & \multicolumn{4}{|c|}{$\begin{array}{c}\text { Preços recebidos causam preços } \\
\text { pagos }\end{array}$} & \multicolumn{4}{|c|}{$\begin{array}{l}\text { Preços pagos causam preços } \\
\text { recebidos }\end{array}$} \\
\hline & \multicolumn{2}{|c|}{ Estatística F } & \multicolumn{2}{|c|}{$\begin{array}{c}\text { Nível de } \\
\text { significância }\end{array}$} & \multicolumn{2}{|c|}{ Estatística F } & \multicolumn{2}{|c|}{$\begin{array}{c}\text { Nível } \\
\text { significância }\end{array}$} \\
\hline & $\begin{array}{c}06 / 86 \text { a } \\
06 / 94\end{array}$ & $\begin{array}{c}07 / 94 \text { a } \\
02 / 04\end{array}$ & $\begin{array}{c}06 / 86 a \\
06 / 94\end{array}$ & $\begin{array}{c}07 / 94 \text { a } \\
02 / 04\end{array}$ & $\begin{array}{c}06 / 86 \text { a } \\
06 / 94\end{array}$ & $\begin{array}{c}07 / 94 \text { a } \\
02 / 04 \\
\end{array}$ & $\begin{array}{c}06 / 86 \text { a } \\
06 / 94\end{array}$ & $\begin{array}{c}07 / 94 \text { a } \\
02 / 04\end{array}$ \\
\hline Índice global & 1,4898 & 6340 & 0,2127 & 0,1461 & 7,2878 & 1,9842 & 0,0000 & 0,0573 \\
\hline - Agrotóxicos & 0,1821 & 3,8079 & 0,8338 & 0,0535 & 6,3592 & 0,5062 & 0,0002 & 0,6789 \\
\hline - Combustíveis & 15,2059 & 1,7885 & 0,0000 & 0,1838 & 5,7183 & 1,5993 & 0,0188 & 0,1557 \\
\hline - Fertilizantes & 0,4844 & 0,9989 & 0,4882 & 0,3965 & 6,8256 & 1,1012 & 0,0001 & 0,3521 \\
\hline - Sementes & 2,5279 & 2,6956 & 0,0353 & 0,0348 & 5,2146 & 3,8903 & 0,0072 & 0,0055 \\
\hline - Serviços & 3,3395 & 2,4881 & 0,0138 & 0,0363 & 1,9428 & 0,6060 & 0,1110 & 0,6125 \\
\hline
\end{tabular}

Fonte: estimativas baseadas em dados da FGV/RJ.

Verificou-se, portanto, que os insumos de circulação regional, como sementes e serviços, tiveram os seus preços influenciados pelos preços recebidos. Neste caso, o preço do produto, ao deslocar a demanda por sementes, modificaria bastante o seu preço, com o que se poderia supor que a sua oferta fosse inelástica. O mesmo valeria em relação aos serviços.

Os resultados da análise indicaram também que os preços recebidos não causaram os preços pagos pelos fertilizantes nos dois períodos, insumo de circulação nacional e internacional, portanto de oferta mais elástica.

Quanto aos agrotóxicos, o seu preço não foi influenciado pelos preços recebidos antes do Plano Real, mas sim após 1994. O primeiro período confirma a hipótese inicial do trabalho, o segundo não. A explicação para a causalidade no segundo período talvez se deva ao fim da inflação. No período de inflação alta, as firmas fornecedoras de agrotóxicos estabelecem os preços para seus produtos sem considerar os preços agrícolas. $\mathrm{O}$ agricultor comprava estes insumos a um preço mais elevado com a esperança de que o preço futuro do produto, elevado pela inflação, compensasse os gastos adicionais. Com a estabilidade econômica, o preço do agrotóxico somente poderia ser mais elevado se o preço do produto também o fosse. Assim, este causaria o preço pago pelo agrotóxico.

Um resultado inesperado foi o preço recebido pelo produto ter causado o preço dos combustíveis antes do Plano Real. Esta causalidade é difícil 
de ser explicada pela teoria apresentada, por tratar-se de um insumo de uso generalizado, com preços administrados pelo governo, em função de variáveis políticas e por fatores internacionais.

Verifica-se, pela Tabela 7, que os preços pagos pelo conjunto dos insumos e por agrotóxicos, combustíveis, fertilizantes e sementes causaram os preços recebidos pelos produtos agropecuários antes do Plano Real. Contudo, após 1994, o efeito das variações dos preços pagos sobre os preços recebidos se reduziu muito, confirmando a hipótese inicial do trabalho.

Após 1994, os preços das sementes e do conjunto dos insumos continuaram influenciando os preços recebidos, porém o preço do conjunto dos insumos apresentando menor significância estatística. Assim, os preços domésticos dos produtos agropecuários dependeriam, no segundo período, muito mais da conjuntura internacional do que de fatores internos.

\section{Conclusões}

Os termos de trocas beneficiaram a agropecuária entre dez. 1986 e fev. 2004, no conjunto, e em relação a fertilizantes, agrotóxicos e sementes. Elas pioraram para serviços e combustíveis, beneficiando a agropecuária principalmente antes de 1994, porém com grandes flutuações. Após o Plano Real, elas continuaram em geral favoráveis e com relativa estabilidade. Porém, considerando-se ago. $94=100$, elas se deterioraram para o total do Brasil e para o Nordeste (exceto Maranhão e Bahia), assim como para o Sudeste e o Sul, com melhorias a partir de 2001 e 2002, indicando possível influência da desvalorização cambial de 1999. Elas deterioraram-se para café, batata inglesa, frango e leite, tanto pela queda de seus preços, como pelo aumento dos preços dos insumos utilizados. Elas foram favoráveis para soja, cacau e arroz, porém com grandes flutuações no período. Como se percebe, nos últimos vinte anos a tese de Prebisch não se verificou para o conjunto da agropecuária brasileira.

Em relação à causalidade de Granger, considerou-se a hipótese de que os preços recebidos pelos agricultores atuariam sobre os preços pagos, através de deslocamentos das curvas de demanda pelos insumos. Assim, o efeito esperado de uma variação do preço recebido pelos produtos agropecuários sobre o preço pago pelos insumos seria tanto maior quanto mais inelástica for a oferta desse fator. Não houve causalidade dos preços rece- 
Relações de Trocas e Causalidade de Granger entre Preços Pagos

e Recebidos pela Agricultura Brasileira, 1986/2004

bidos pela agropecuária sobre os preços pagos pelo conjunto dos insumos, em todo o período; isso indicaria que a oferta de insumos é elástica, ou seja, mudanças na demanda gerando pouca variação de preços.

Para os insumos, verificou-se que os preços recebidos pelos agricultores não causaram os preços dos fertilizantes, mas causaram os preços das sementes e serviços (nos dois períodos). Nestes três casos, a hipótese de menor ou maior elasticidade preço de oferta do insumo poderia ser a explicação. A oferta de fertilizantes (circulação nacional), poderia ser elástica para regiões e produtos específicos. As ofertas de sementes, destinadas a culturas específicas, assim como a oferta de serviços, ambas locais, poderiam ser inelásticas.

Os preços pagos pelos insumos atuariam sobre os preços recebidos pela agropecuária através de deslocamentos das curvas de oferta dos produtos agropecuários. O efeito seria tanto maior sobre os preços agrícolas quanto mais inelástica fosse a demanda pelo produto agropecuário. Assim, espera-se que as demandas pelos produtos agropecuários tenham se tornado mais elásticas com a abertura econômica da década de 1990 . Portanto, o efeito dos preços pagos seria maior no período anterior ao Plano Real do que no posterior. Os resultados indicam que foi isso que aconteceu. $\mathrm{O}$ efeito dos preços pagos pelo conjunto dos insumos sobre os preços recebidos pela agropecuária foi muito significativo estatisticamente antes do Plano Real, mas significante apenas a 10\% após o mesmo. Do mesmo modo, considerando-se individualmente, os preços pagos para cada um dos insumos, exceto serviços, causaram os preços recebidos antes do Plano Real. No entanto, após 1994, com exceção das sementes, nenhum insumo considerado isoladamente causou os preços recebidos pela agropecuária brasileira.

Conclui-se que as mudanças nas relações de trocas na agropecuária, em alguns estados e para produtos específicos, podem ser explicadas por fatores locais influenciando a oferta de insumos em nível regional, e por fatores nacionais, como maior abertura da economia, com reflexos regionais, que podem ter afetado particularmente alguns produtos. Contudo, o fim da inflação alta trouxe maior estabilidade para a agropecuária brasileira, com os preços pagos aos diferentes insumos influenciando menos os preços recebidos pelos agricultores. 


\section{Referências bibliográficas}

ALVES, E. Quem ganhou e quem perdeu com a modernização da agricultura brasileira. Revista de Economia e Sociologia Rural. Brasília: SOBER, vol. 39, n. 3, 2001.

GRANGER, C. W. J.; HUANG, B. N. e YANG, C. W. A Bivariate Causality Between Stock Prices and Exchange Rates: Evidence from Recent Asia FLU. Discussion Paper 98-09. Department of Economics. University of California. San Diego. 1998.

HELFAND, S. M. \& REZENDE, G. C. A agricultura brasileira nos anos de 1990: o impacto das reformas de políticas. In: GASQUES, J. G. \& CONCEIÇÃO, J. C. P. R. Transformações da agricultura e políticas públicas. Brasília: IPEA, 2001, cap. 6, p. 248-301.

JOHNSTON, Bruce F. \& MELLOR, J. W. El papel de la agricultura en el desarrollo económico. El Trimestre Económico, primeiro trimestre, 1961.

MAFIOLETTI, R. L. Formação de preços na cadeia agroindustrial da soja na década de 90. Revista de Economia e Sociologia Rural. Brasília: SOBER, vol. 39, n. 4, 2001.

PATTERSON, K. An Introduction to Applied Econometrics: a time series approach. St. Martin's Press, Scholarly and Reference Division. Nova Iorque. 2000.

PREBISCH, Raul. O desenvolvimento econômico da América Latina e seus principais problemas. Revista Brasileira de Economia. Rio de Janeiro: FGV, ano 3, n. 3, set. 1949

REZENDE, G. C. Estado, Macroeconomia e Agricultura no Brasil. Porto Alegre: Editora da UFRGS, 2003.

SOUZA, Nali de Jesus. Desenvolvimento econômico. 5 ed. São Paulo: Atlas, 2005.

Recebido em setembro de 2004 e revisto em abril de 2005. 